\title{
Risks and Implications for Decision-Making Processes Associated with Existing Design Codes or Their Non-Existence
}

\author{
Jan Błachut*, Dariusz Sala*
}

\begin{abstract}
The buckling phenomenon is a perplexing and unresolved issue in many safety critical structures; as a result, it has been heavily regulated. The existence of regulations would normally benefit modern decision-making tools. But there are various obstacles coming from real-life situations. In order to illustrate the above and draw awareness to the problem, the paper chooses the buckling of shells and discusses (i) the case of an internally pressurized dome found in a plane's fuselage that failed during a routine flight, (ii) a case where advances in structural mechanics challenge the existing design codes (i.e., metallic domes in pressure vessels), and (iii) a case of extracting rich seabed resources where efficient buoyancy units are required. In the last-mentioned case, the paper points towards the use of advanced Carbon Fiber Plastics (CFRPs) and illustrates this by a failed CFRP dome manufactured from a woven fabric (a topic still within the research sphere of activities). Cases of several other industrial failures caused by buckling are also provided. Finally, the paper highlights the risks to the decision-making processes due to the growing tendencies of eliminating the records of disastrous events from public domains through confidentiality arrangements and the erosion of the existing human know-how.
\end{abstract}

Keywords: buckling, pressure loading, imperfections, structural components

Mathematics Subject Classification: 74G60

Submitted: January 09, 2018

Revised: May 08, 2018

\section{INTRODUCTION}

Nowadays, computer programs are responsible for a large portion of the decision-making processes. This applies to many industrial activities. Computer codes facilitate the identification of processes, help analyze and interpret data, and estimate the consequences of any decisions made. These decision support systems are meant to cover all phases of the decision-making process; e.g., Keen, Scott-Morton (1978),

* AGH University of Science and Technology, Faculty of Management, Kraków, Poland, e-mail: blachut@zarz.agh.edu.pl 
Power (1999). The origin of their development is usually associated with the Carnegie Institute of Technology and MIT. The latter is credited with the development of the first codes aimed at automated/structured decision making (Power, 1999). The current systems tend to apply modern techniques of data acquisition and processing. This includes active computer systems (self-learning and/or adaptive) that are capable of adjusting themselves to the need of a specific decision making requirement and environment. It is worth noting that such systems are capable of dealing with imperfect data like imprecision, lack of consistency, limited certainty, etc. They are also capable of delivering strategic recommendations as well as detailed operational reports for a given industrial entity based on their own data - see Figure 1.

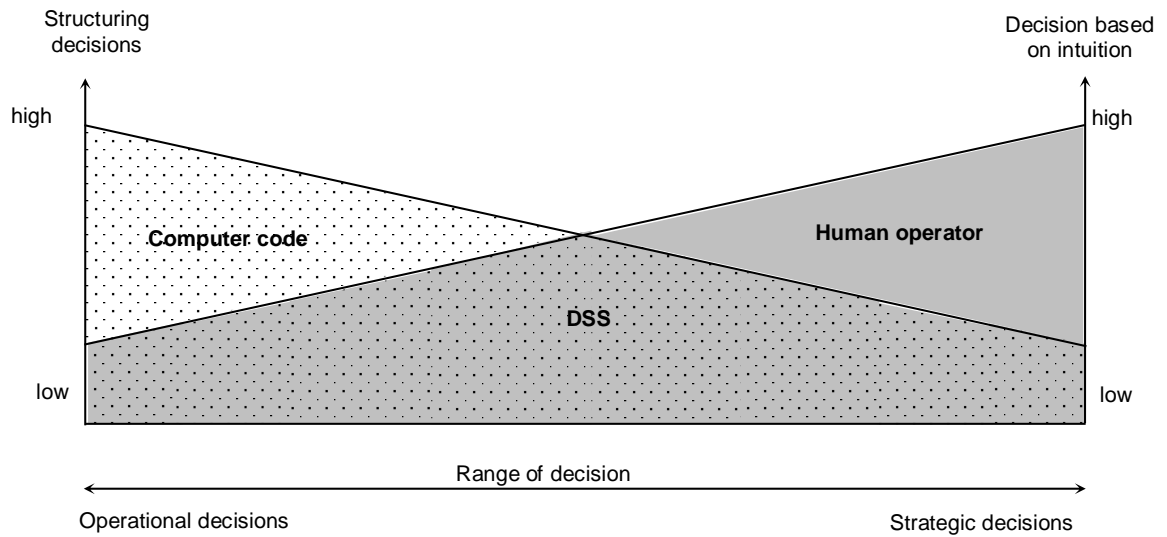

Fig. 1. Scheme of decision-making processes and their interaction (Sala, 2007, p. 35)

There are also decision support systems that have on-line access to data and to analytical decision-making models. This in turn can efficiently support decision processes, especially when standard computer programs of lower rankings are either unable to find solution or it would be uneconomical to use them. A subset of computer support systems provides information for top company management personnel. These executive information systems (as they are called) gather relevant data from across all levels of a company, sort it out, and prepare it in a format that can explicitly help managers to make efficient decisions on a day-to-day basis. A further level of an executive information system is associated with partially processed data, some conclusions made, and the available partial interpretations and recommendations. This kind of information system is aimed at top levels of managers who make strategic decisions. Another form of a decision support system is based on the use of business intelligence (Biere, 2003). This kind of system uses data from all available sources as well as data about the personnel's know-how as well as the experience of all those who are involved in the business decisions. Elements of feedback from the consumers and partners are also included in this kind of system modus operandi - see Figure 2.

The inclusion of a feedback loop into decision making has created a superior tool (as expected). For example, users become aware of past decisions, the corrective actions taken, and the sensitivities of the adjustments. Fresh inputs can be added 
to the system as new technologies emerge or business environment changes. Bits of information related to corporation individuals and their involvement in a company's well-being, creativity, and motivations are also gathered. They constitute personal information about the company and give managers a better appreciation of the corporation workforce (Szyjewski, 2003).

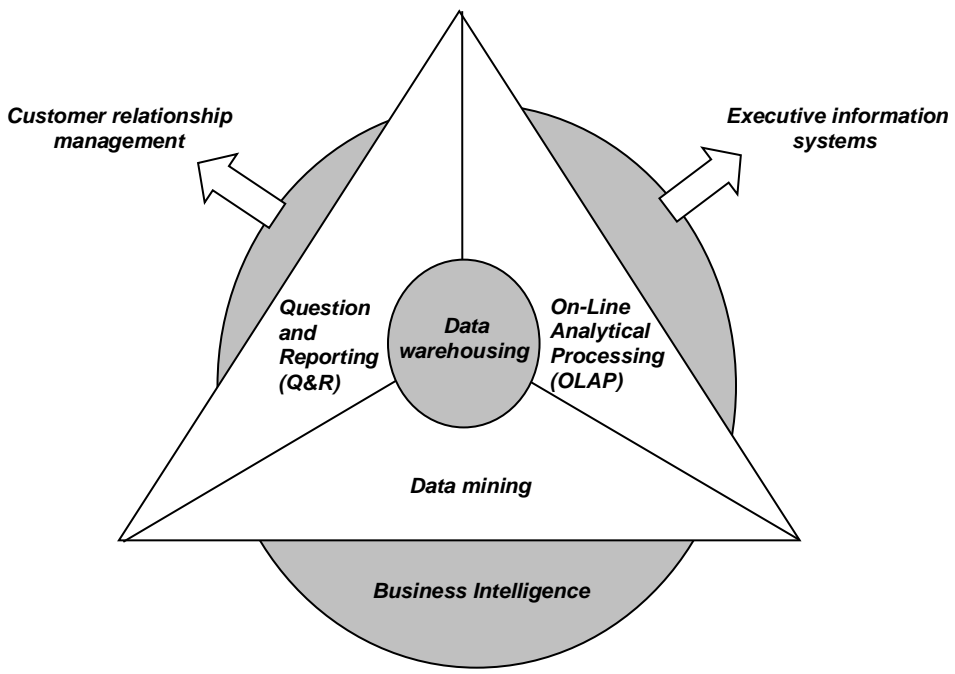

Fig. 2. Illustration of information systems and their relative positioning, (Sala, 2007, p. 36)

A relatively new development in decision-making processes is associated with data mining. The recovered data is usually subjected to online analytical processing, which provides the instigator with a multi-faceted analysis of the data found.

At face value, the above approaches can deal with imprecise/incomplete data and estimate the consequences of the decisions made. But it is unclear how (if at all) the support systems can deal with some engineering activities where a high level of safety is required due to the dangerous phenomenon associated with buckling (e.g., Singer et al., 2002; Błachut, 2014). In cases like these, safety design codes have been developed and they have become legally binding in many instances. Virtually all countries have sets of their own rules; e.g., British Standards in the U.K. (BS), Industrial Standards in Germany (DIN), or Polish Standards in Poland (PN). One specific area where these standards are applied is related to pressure vessels. Despite the advances in science, manufacturing, and materials, these design codes still rely on phenomenological data obtained from experiments over the past decades (Singer et al., 2002). Pressure vessels are used across industries on land, under the sea, and in the air. Their primary loading is usually internal or external pressure. As far as the geometry is concerned, they are built from cylindrical shells closed by domed ends. One perplexing issue (and still not satisfactorily resolved) is the large sensitivity of load-carrying capacity to initial geometric imperfections. This is particularly present in axially compressed cylinders and externally pressurized domed closures due to the possibility of buckling. In what follows, the paper mainly concentrates on domed closures onto cylindrical vessels. 


\section{SCOPE}

This paper aims to highlight buckling/collapse issues in pressurized domed closures. On one hand, the design codes are meant to secure the safe use of pressure components; however, the arrival of new business opportunities require the codes to be upgraded or even developed. This, however, is a slow process, and the safety of vital engineering tasking can only be secured by the rigorous application of tried and reliable methodologies. As advances in mechanics, computations, and materials challenge the existing design by rule approaches, the paper identifies some bottlenecks that are likely to affect automated decision support processes.

\section{BACKGROUND}

One intense and important human activity at the frontier of technological development is deep-sea exploration. It transpires that, at the moment, there is a quiet colonization of the oceans' seabeds. While the extraction of oil and gas from seabeds has continued for several decades, it is the availability of rare raw material that drives deep-sea research (cobalt, copper, manganese, silver, tungsten, gold, etc.). In many instances, it is estimated that these materials can be extracted at $30 \%$ of on-land costs. There are only a few nations that have the required manned vehicles capable of reaching a depth of $6 \mathrm{~km}$ - see Figure 3 (with the Chinese Jiaolong vehicle rated at $7 \mathrm{~km}$ just announced).

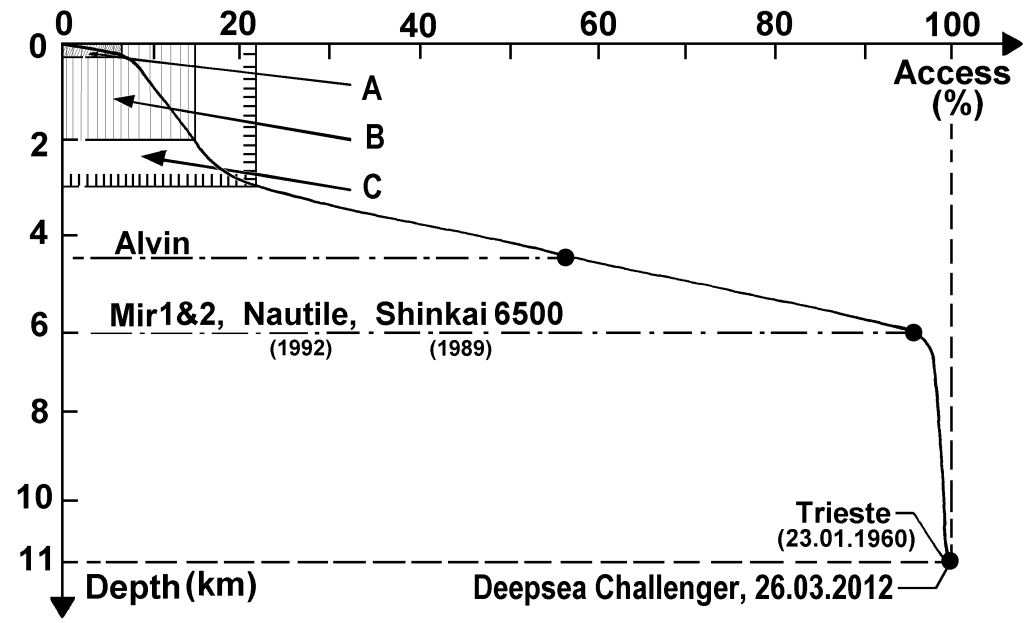

Fig. 3. Access to seabed versus exploration depth (current and planned). Available vehicles are also denoted ( $A \equiv$ current, North Sea; $B \equiv$ current, Gulf of Mexico, coastal waters of Brazil \& Nigeria; $C \equiv$ planned, researched)

The main technological obstacles are the availability of sufficient buoyancy units. These are shells of hemispherical, torispherical, or elliptical shapes. Their strength is greatly affected by sensitivity to small deviations from a perfect shape. Hence, all 
experimental data for metallic heads has been collated, and a lower bound was drawn to them. Next, a safety zone was proposed by lowering the design curve (as shown in Figure 4).

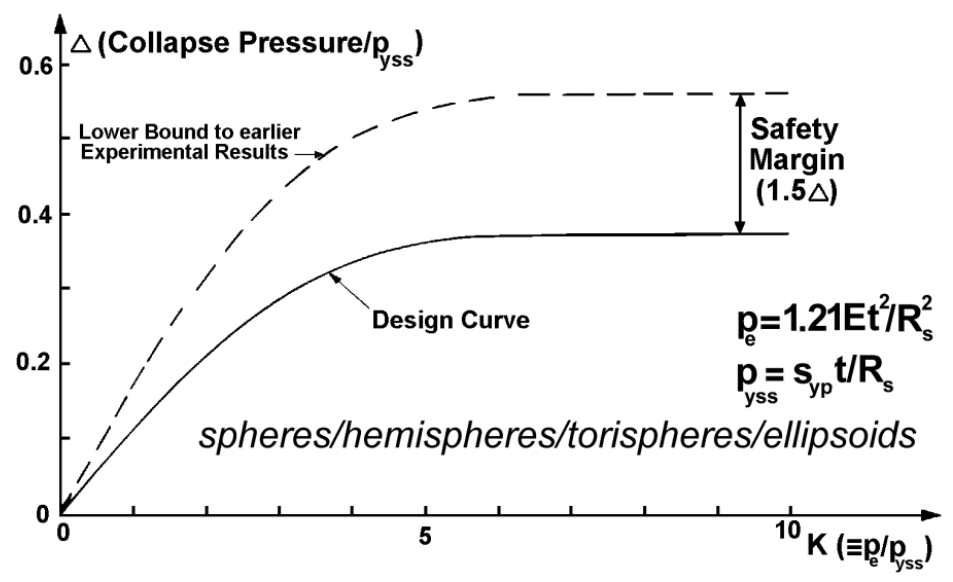

Fig. 4. Lower bound to known experimental data and design curve with safety margin

For a while, designers remained assured that no failure could occur within a safety buffer zone. But this comfort has been removed by advanced computations backed by the testing of industrial and laboratory shells shown in Figure 5 (Błachut, 1998).

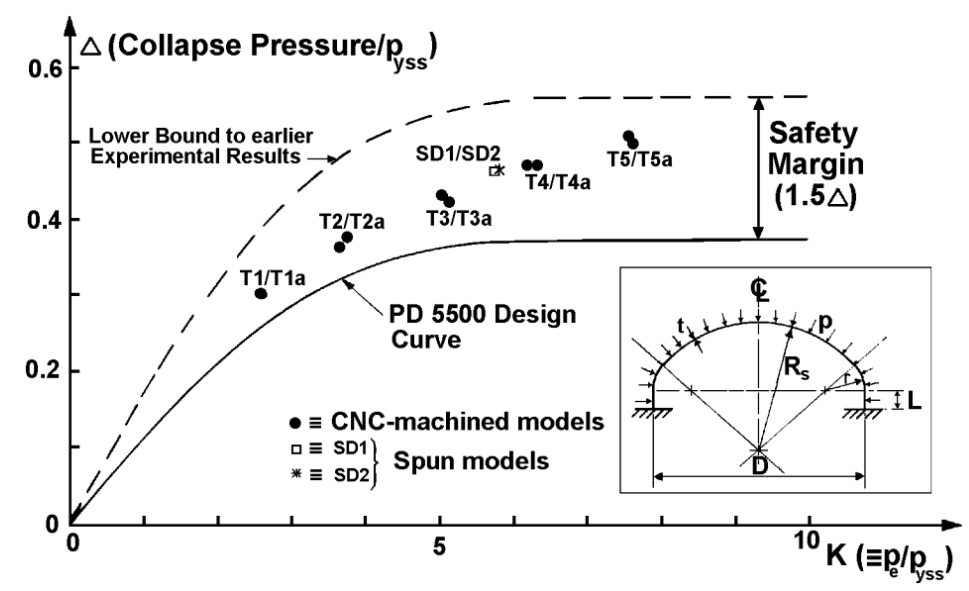

Fig. 5. Illustration of how safety margin has been compromised by experimental test data

This implies that an additional safety margin has to be considered for a specific product and its application. Industries have looked for new materials from which buoyancy units could be made. One possibility was for domes manufactured from composites $(\mathrm{CFRP}=$ Carbon Fiber Reinforced Plastics $)$. But the results of these expensive research programs are not instantly available in the public domain - mostly 
due to their commercial/security sensitivity. Sponsors of research into novel structures frequently remove critical information from the public domain. A good example is the study by Didier (2014), where the supplement containing critical experimental data and conclusions was only available to examiners during the $\mathrm{PhD}$ viva and then made confidential.

\section{CASE STUDIES}

There are situations where no design code exists and structures have to be built in accordance with the best know-how at a time, which sometimes does not secure a safe future use of a product (as illustrated next).

\subsection{FAILURE OF REAR BULKHEAD}

Consider an L1011-385 wide-body airplane that has been in service for decades and is capable of carrying 400 passengers and 20 air crew. On a flight from Tenerife to Manchester in 1995 (when the aircraft was approximately halfway between Tenerife and Faro), the flight crew heard a loud bang. As the cabin pressure started to change, the flight crew released the oxygen masks, and the aircraft immediately commenced an emergency descent. Apart from the pressurization failure, the aircraft had handled normally. During the transit to Faro, $4000 \mathrm{~kg}$ of fuel was dumped to reduce the aircraft's landing weight to $160,000 \mathrm{~kg}$; it then landed safely. As the decompression happened at the rear bulkhead, it was the subject of careful investigation at Farnborough/UK by the Air Accident Investigation Board (AAIB, 1996). The rear pressure bulkhead is a thin-shell structure comprising a series of one-mm-thick panels lap-jointed to form a dome-shaped pressure membrane of an approximately hemispherical profile. On the passenger side, the shell was reinforced by a grid of stringers and rings (as seen in Figure 6).

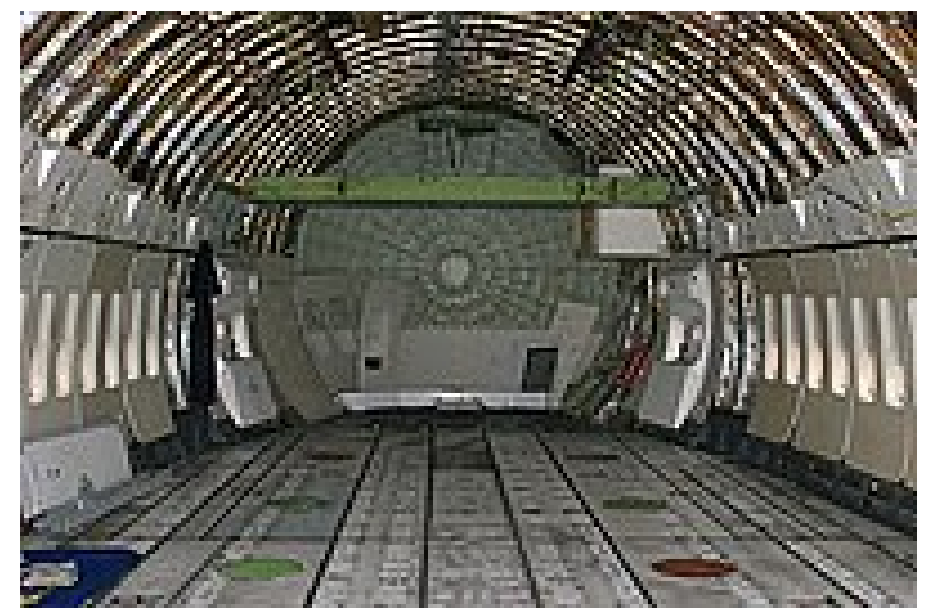

Fig. 6. View of rear bulkhead in L1011 wide-body plane reinforced by stringers and rings on internal passenger side 
The purpose of the reinforcing grid was to limit the size of any rupture that might occur. The apparent cause of the cabin depressurization was a rupture of the skin within one grid cell. It transpired that, during each flight, the skin buckled after take-off and snapped back to normal shape before landing. The large number of these 'in' and 'out' buckling snaps caused fatigue in the material and the subsequent fracture. Luckily, the venting of cabin pressure did not damage other vital elements of the aircraft structure in this case. A catastrophic structural failure that can follow from a pressure bulkhead failure due to the release of pressurized cabin air into parts of the aft fuselage let to a major accident of a Japan Airlines Boeing 747 in 1985, resulting in the deaths of more than 500 people. The rear bulkhead of the B747 had only stringer reinforcements (see Fig. 7); when the rupture occurred, the increased flow of cabin air effectively disabled the aircraft.

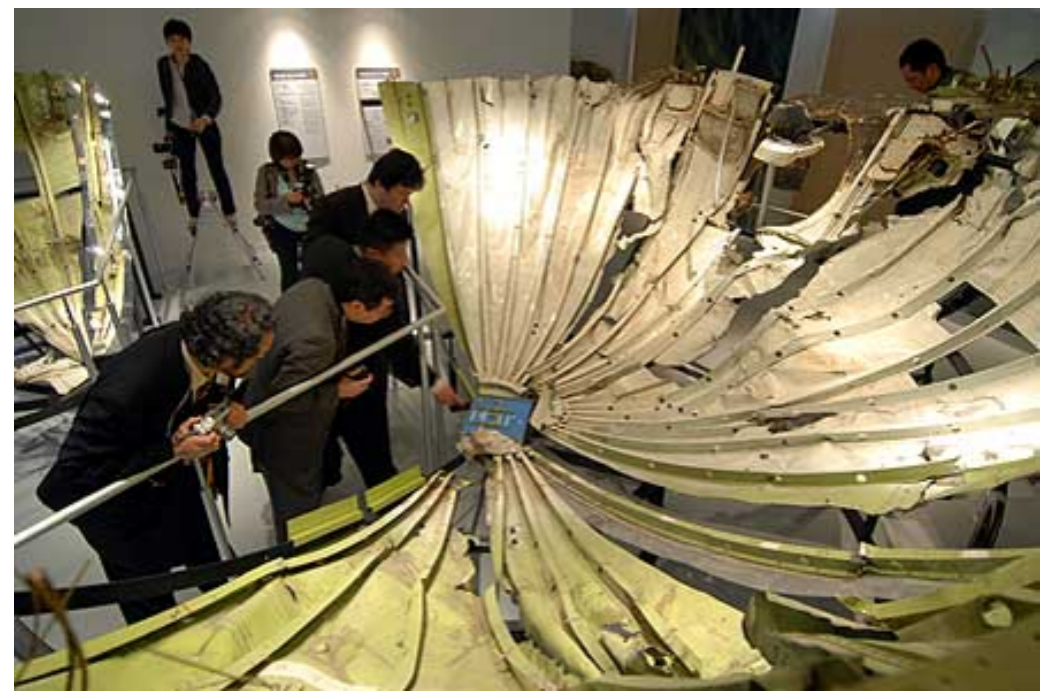

Fig. 7. Fragments of recovered rear bulkhead of JAL B747 plane in Tokyo airport museum

It must be said that predicting the buckling of a rear bulkhead under operational loading is difficult. At the time when the above wide-body aircraft were designed (in the sixties and early seventies of the last century), there were no reliable tools for predicting this mechanism of failure. Equally surprising were the crash investigator's recommendations in the case of the B747, which merely stated 'redesign the rear bulkhead' without giving any reasons behind the statement. After the occurrence of the above two cases, a major effort was directed towards the safety of rear bulkheads. The difficulty of predicting a 'buckling dimpling' of a grid-reinforced structure is also illustrated in Figure 8. It shows a glider's skin in a buckled condition (dimples), which disappears after another maneuver of the glider. In this instance, the internal grid reinforcement secures the integrity of the wing. But after many 'in' and 'out' buckling snaps, the skin can rupture; this can lead to the free fall of the glider. 


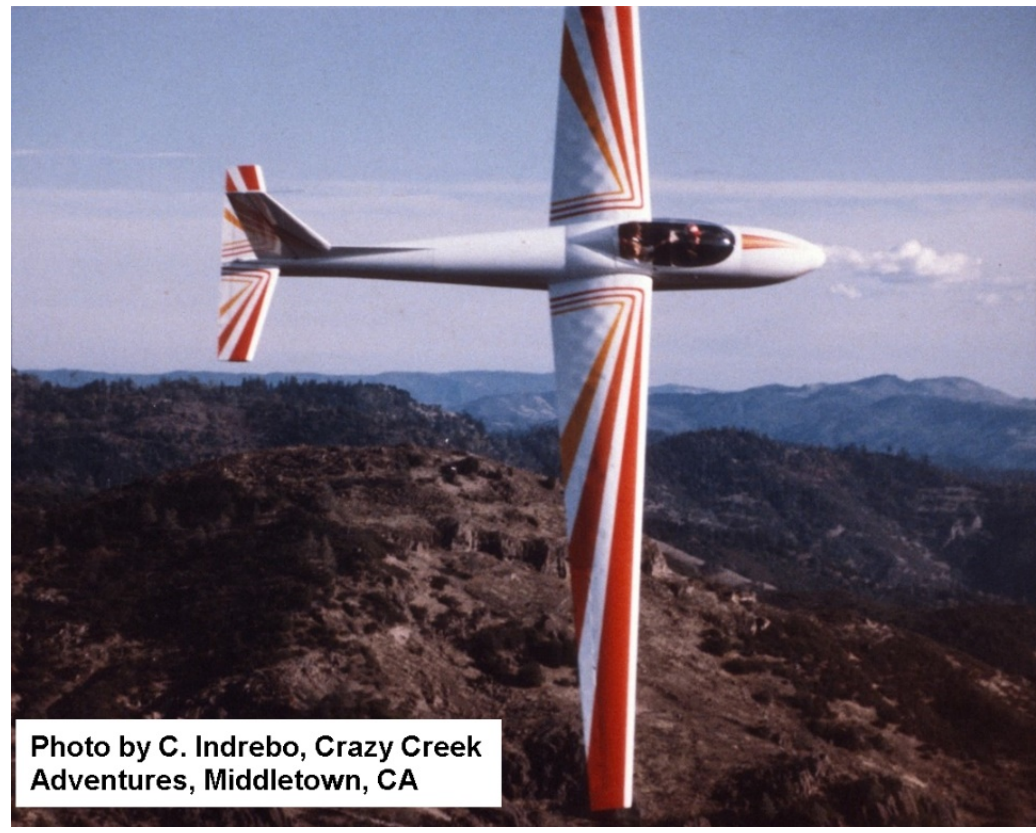

Fig. 8. View of dangerous inward dimples in wings of glider (with permission of Dr D. Bushnell, Lockheed Martin, Palo Alto (Bushnell, Bushnell, 2017))

\subsection{FAILURE OF COMPOSITE DOME}

CFRP domes have been researched for their possible use in deep-sea activities. As with each novel program, one had to address the manufacturing processes and develop a theoretical predictive method for the buckling/collapse of these pressure components. Figure 9 depicts a collapsed 30-ply CFRP head made from draped carbon fabric (Błachut, 2014).

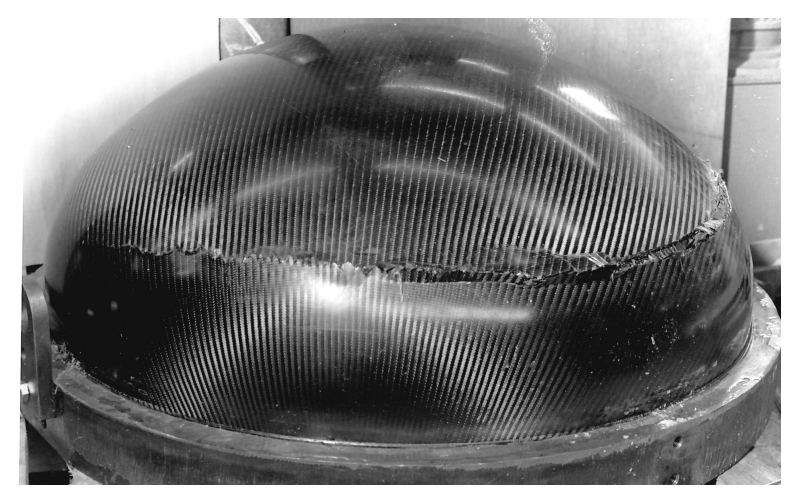

Fig. 9. Photograph of failed 0.8-m-diameter CFRP dome 
A question here arises on how the accumulation of the know-how in this research program can efficiently be used in automated decision-making tools? One approach might be 'wait and see.' But this may equally lead to the loss of business opportunities once others can take these vanguard developments on board.

\subsection{FAILURE OF IMPERFECT DOME}

As mentioned earlier, imperfections in domes seriously affect the magnitude of their buckling strength (i.e., they lower it). Consider as an example a CFRP torisphere in which two types of shape imperfections exit. The first one is affine to an eigenshape, and the second corresponds to a local inward dimple. A sample of the computed results is depicted in Figure 10.

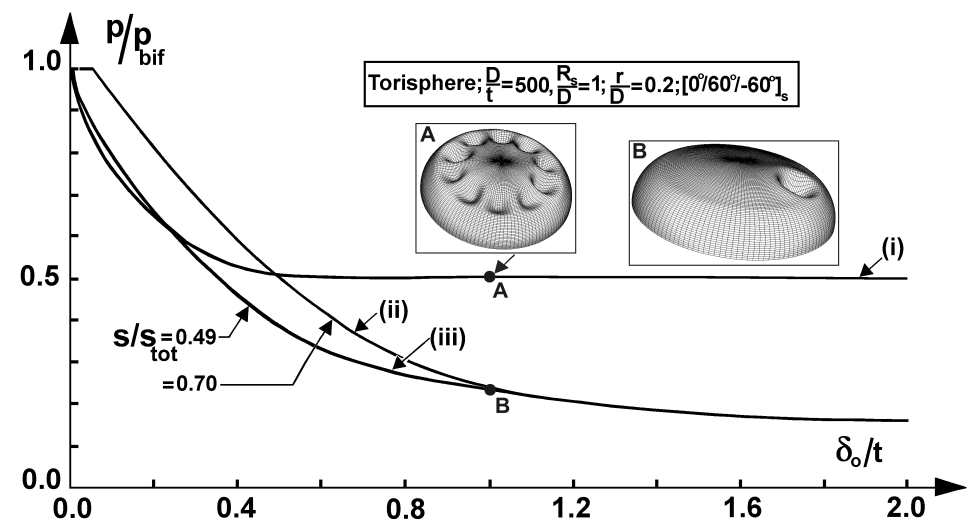

Fig. 10. Sensitivity of buckling pressure (p) to amplitude of inward shape deviation ( $\delta$ )

It is seen here that the amplitude of imperfection amounting to one wall thickness $(t)$ reduces the load carrying capacity by $75 \%$. This is a very serious erosion of buckling strength. But shape imperfection is not the only possible contribution responsible for lowering the load-carrying capacity. There are imperfections in material properties, boundary conditions, load application, or variation in the wall thickness. The ongoing research here is unable to resolve these issues unequivocally - see: Shell Buckling Imperfection Sensitivity, Chapter in Bushnell, Bushnell (2017). Hence, the accumulated know-how backed by selective experimentation is required for the continuous upgrade of design codes. It is worth noting here that NASA (NASA, 1969), for example, is still using the design rule for imperfect structures that were developed in the sixties of the last century.

\subsection{PICTURES OF FAILED INDUSTRIAL VESSELS}

The study by Catriona de Paor (2010) provides a number of failed industrial structures where buckling was the responsible mode. It can be seen in Figure 11 how application-wide and costly these failures can be. Many industrial failures are, unfortunately, 
hidden from the public eye. It appears that the main cause of this is associated with pending legal processes and worries about the professional standing/image of the companies.

a)

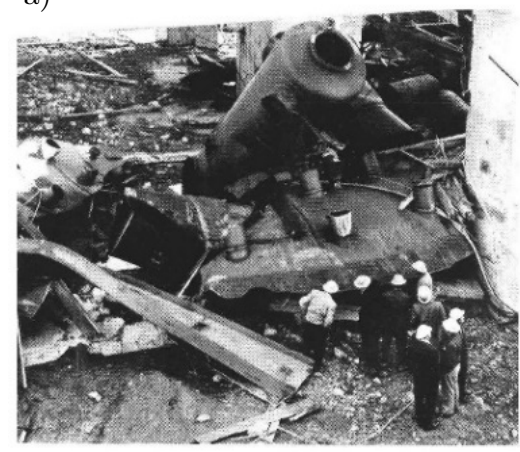

c)

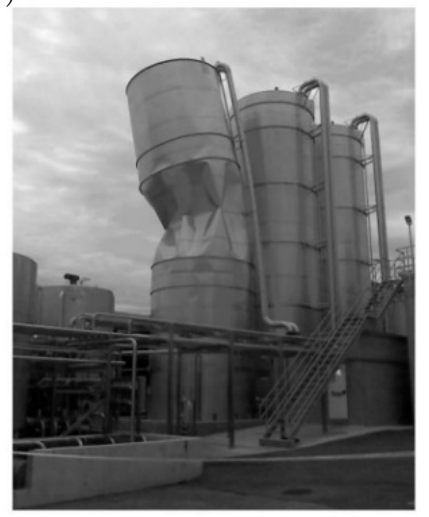

b)

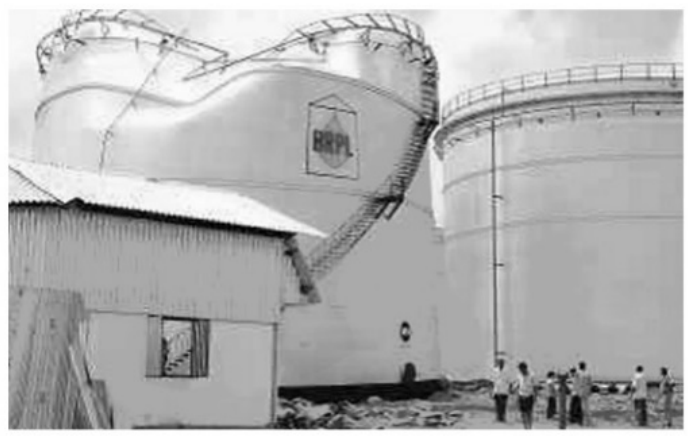

d)

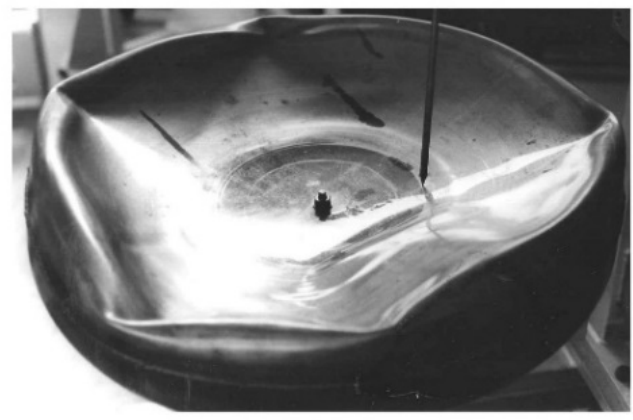

Fig. 11. Sample of structures failed due to insufficient buckling strength Note: cases 'b' \& 'c' from Catriona de Paor (2010)

\section{CLOSURE AND CONCLUSIONS}

It is clear from the above that engineering activities where buckling is a possibility constitutes a challenging environment for decision-making processes. Within the area of existing design codes, one can accept solutions with a reasonable confidence (although they might appear too conservative at first sight). It is essential here that one has to carefully adhere to the recommended envelopes of shape, loading, boundary conditions, materials, etc. Here, however, it has been recently argued that modern computing tools can be used to replace the existing rules (mostly based on experimentation). The term 'design by analysis' has now been coined (Rotter, 2018). It appears that this route has to be used very carefully and only by skilled personnel. At the moment, it is 
unclear how the future of this strategy will unfold. Saying that, decision processes will have to take notice of this development.

At the frontiers of human activities (deep-sea exploration, missions to Mars, nano-technology) where definitive business answers are fuzzy, it is felt that active monitoring should suffice for the moment.

\section{REFERENCES}

AAIB (Air Accident Investigation Branch), UK, 1996. Bulletin No. 2/96, EW/A95/6/1, pp. 34-39.

Biere, M., 2003. Business Intelligence for the Enterprise. Prentice Hall PTR/IBM Press.

Błachut, J., 1998. Buckling of sharp knuckle torispheres under external pressure. Thin-Walled Structures, 30, pp. 55-77.

Błachut, J., 2014. Experimental perspective on the buckling of pressure vessel components. Applied Mechanics Reviews, Transactions of the ASME, 66, pp. 1-51.

Bushnell, D., Bushnell, W.D., 2017, Shell Buckling, available at http://www. shellbuckling. com [access: August 2018].

Catriona de Paor, C., 2010. The effect of random geometric imperfections on the buckling of thin cylindrical shells due to external pressure. PhD Thesis, University of Cork, Ireland.

Didier, J., 2014. Etude du comportoment au flambage des coques cylindriques multicouches metal/materiau mousse sous chargements combines pression interne/cisaillement/flexion. PhD Thesis, INSA, Lyon, France.

Keen, P.G.W, Scott-Morton, M.S., 1978. Decision support systems: an organizational perspective. Addison-Wesley, Reading, MA, USA.

NASA, 1969. Buckling of Thin-Walled Doubly Curved Shells. NASA Space Vehicle Design Criteria, Report No. NASA SP-8032.

Power, D.J., 1999. A brief history of decision support systems, available at http:// dssresources.com/history/dsshistory.html [access: August 2018].

Rotter, J.M., 2018. Challenges and their resolution in both philosophy and process to exploit advanced computation in shell structure design. In: Pietraszkiewicz, W., Witkowski, W. (eds.), Shell Structures - Theory and Applications - Vol. 4'. CRC Press Taylor \& Francis, London, pp. 41-50.

Sala, D., 2007. Wspomaganie decyzji w procesach przygotowania produkcji z wykorzystaniem systemu ekspertowego [Decision supporting in production preparation processes using an expert system]. PhD Thesis, AGH University of Science and Technology, Krakow, Poland.

Singer, J., Arbocz, J., Weller, T., 2002. Initial Imperfections. In: Singer, J., Arbocz, J., Weller, T., Buckling experiments - experimental methods in buckling of thin-walled structures. Vol. 2, John Wiley \& Sons, Chichester, NY, USA, pp. 809-862.

Szyjewski, Z., 2003, Zarzadzanie wiedza korporacyjna. Pro Dialog: Programowanie i Zastosowanie Komputerów, 16, pp. 23-35. 